\section{Pressured Speech}

Natalie Dattilo

Department of Psychiatry, Indiana University

School of Medicine, Indianapolis, IN, USA

\section{Definition}

Accelerated speech that is increased in amount and difficult or impossible to interrupt. Affected persons may present with speech that is incessant, rapid, loud, or emphatic. It is not uncommon for the person to talk without any social exchange and continue even though no one is listening. Typically considered a symptom of schizophrenia; also occurs during the course of a manic episode.

\section{See Also}

- Bipolar I Disorder

- Manic Episode

- Schizophrenia

\section{References and Readings}

American Psychiatric Association. (2013). Diagnostic and statistical manual of mental disorders: DSM-5. Washington, DC: American Psychiatric Association.

Andreasen, N. C. (1979). Thought, language, and communication disorders: Clinical assessment, definition of terms, and evaluation of their reliability. Archives of General Psychiatry, 36, 1315-1321.

Sadock, B. J., \& Sadock, V. A. (2007). Kaplan \& Sadock's synopsis of psychiatry: Behavioral sciences/clinical psychiatry (10th ed.). Philadelphia: Lippincott Williams \& Wilkins. 